\title{
Rubidium Chloride Rb-82
}

National Cancer Institute

\section{Source}

National Cancer Institute. Rubidium Chloride Rb-82. NCI Thesaurus. Code C47711.

The chloride salt form of rubidium-82, a positron emitting isotope used as an imaging tool. Rubidium chloride Rb-82 accumulates in myocardial cells and other tissues, and can be evaluated as a function of blood flow. By scintigraphic means, areas with decreased blood flow can be visualized due to decreased uptake of $\mathrm{Rb}-82$. 